\title{
Low-cost electronic control with resistive joystick and arduino for children electric wheelchair
}

\begin{abstract}
Wheelchair is an assistive technology device that allows people with physical disability to have more independence, quality of life and social inclusion. The lack of access to a wheelchair is a serious problem all around the world. Almost 20 million people in the world do not have access to a wheelchair due to the high costs. The electric wheelchair is a special device for people with severe physical disability (quadriplegia, cerebral palsy and others). The lack of access to electric wheelchairs, due to the high costs, is a relevant factor in lack of inclusion of disabled children in formal education. The aim of this study was to develop and evaluate a low cost electronic control for children electric wheelchair. The methodology was based on constructing and testing an electronic prototype using Arduino and a low-cost resistor position sensor for electric wheelchair control.
\end{abstract}

Keywords: resistor joystick, electric wheelchair, arduino, H-bridge
Volume 3 Issue 2 - 2017

\author{
Maria Elizete Kunkel,' Filipe Loyola Lopes, ${ }^{2}$ \\ Henrique Alves De Amorim' \\ IInstitute of Science and Technology, Federal University of São \\ Paulo, Brazil \\ ${ }^{2}$ Modeling and Applied Social Sciences, Federal University of \\ $A B C$, Brazil
}

\begin{abstract}
Correspondence: Maria Elizete Kunkel, Institute of Science and Technology, Federal University of São Paulo, Av Cesare Monsueto Giulio Lattes, I 1 I, Santa Inês I223 I-280, São José dos Campos, São Paulo, Brazil, Email elizete.kunkels@gmail.com
\end{abstract}

Received: September 05, 2017 | Published: September 18, 2017

\section{Introduction}

The wheelchair is as an assistive technology device fundamental for mobility and to promote the independence, quality of life and social inclusion of people with motor disabilities. ${ }^{1}$ In the world, approximately $1 \%$ of the population needs a wheelchair, but 20 million do not have access to it. ${ }^{2}$ An electric wheelchair (EWC) reduce the effort of the user or his caregiver during propulsion being indispensable in three situations: a) User with severe motor disability (tetraplegia, cerebral palsy, advanced multiple sclerosis, among others); b) User unable to perform physical effort (elderly, cardiopathy, obese, among others) or c) User that needs locomotion in long distances. ${ }^{3,4}$ However, EWC has been indicated as a limiting factor in social inclusion due to high technology costs (average of USD 4,000.00). This is a serious problem, because the largest part of disabled people are part of the low-income population. The lack of access to electric wheelchairs for children is an important factor in the lack of access for children with motor disabilities in formal education. ${ }^{5}$ The purpose of this study is to develop a control system for children's EWC and test it on a children's EWC frame. It was based on resistor joystick (position sensor), H-bridge and an opensource electronic development Arduino platform. With this research we are developing and spreading the control knowledge of EWC aiming at reducing the costs of assistive technology.

\section{Experimental methods}

Figure 1 illustrates the resistive sensor and shows a blocks diagram of the electronic control of the EWC. The electronic system was implemented with a platform compatible with an Arduino model UNO R3 (Aduino, Ivrea, Italy). That platform has an ATmega 328P microcontroller, $16 \mathrm{MHz}$ clock, $5 \mathrm{~V}$ battery, $32 \mathrm{~KB}$ flash memory, 2 KB SRAM memory, $1 \mathrm{~KB}$ EEPROM memory, 6 analogic input and 14 digital input or output. Into the 14 digital doors, 6 Pulse Width Modulation (PWM). The firmware was developed in the Wiring language, based on $\mathrm{C} / \mathrm{C}++$, dedicated to the development of the platform. A resistive model joystick (SparkFun Eletronics, Boulder, EUA) was used for the man-machine interface. The component has input for $5 \mathrm{~V}$ supply, two analogic outputs ( $\mathrm{X}$ and $\mathrm{Y}$ axis) and a digital output. ${ }^{6}$ Two H-bridge Shields were used to drive the motors. These circuits are driven by low current, capable of feeding and controlling the direction of rotation of direct current (DC) motors. ${ }^{7}$ The H-bridge circuit is based on the integrated circuit (IC) BTS7960 (Infineon Technologies, Neubiberg, Germany). This component has field-effect transistors (MOSFETs). Therefore, they consume low electric current $(7 \mu \mathrm{A})$ for the gate and have a typical current of $43 \mathrm{~A}$ at their output. The BTS IC works in PWM frequencies up to $25 \mathrm{kHz}$, allowing the motor speed to be controlled in addition to the direction of rotation. ${ }^{8}$

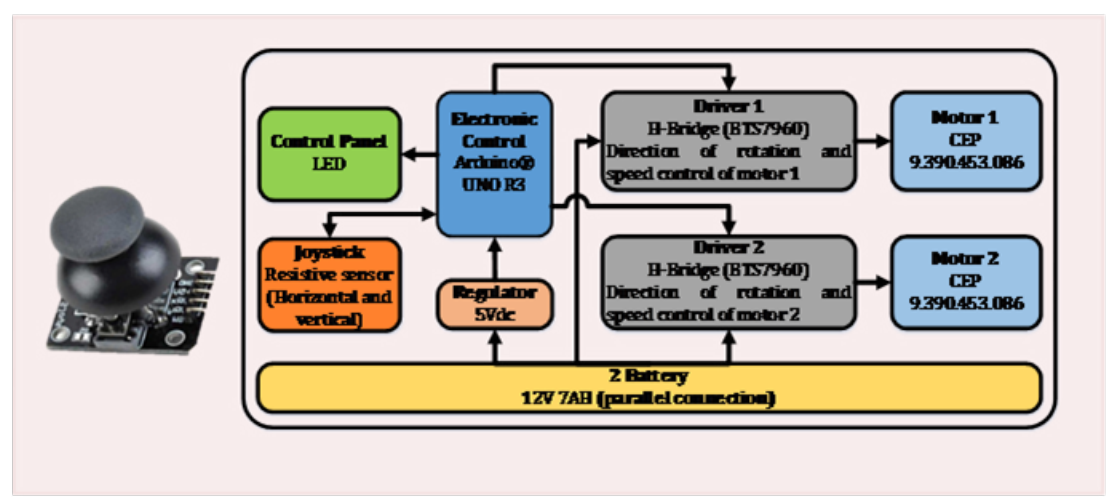

Figure I Electronic circuit of the wheelchair control: Resistive sensor (left) and diagram (right). 
Two motors were used for the propulsion of the EWC (engine coupled to the speed reducer). The model is CEP 9.390.453.086 (Bosch, Stuttgart, German) and it has $12 \mathrm{~V}, 5.5 \mathrm{~A}$ and $25 \mathrm{~W}$ (nominal power), $38 \mathrm{rpm}$ and nominal torque of $6 \mathrm{Nm}$. The power source supply were two lead acid batteries 12V 7AH (Unipower Group, Extrema, Brazil). A circuit with LM7805 IC voltage regulator (Farchild Semiconductor, Sunnyvale, USA) was used to convert the $12 \mathrm{~V}$ voltage of the batteries to $5 \mathrm{~V}$. The resistive joystick circuit and control panel were connected to the 5VDC and GND potentials from the Arduino. The performance tests were made with the electronic control system applied to a children EWC framework, built with PVC pipes, weighing $15 \mathrm{~kg}$, general dimensions of $45 \times 73 \times 100 \mathrm{~cm}$ (width, depth and height) and 6 inches wheels. ${ }^{9}$ The tests were carried out with additional weights of $5 \mathrm{~kg}, 10 \mathrm{~kg}$ and $15 \mathrm{~kg}$, simulating a child. The EWC prototype was submitted to nine field testes, where trajectories of approximately $20 \mathrm{~m}$ were performed on flat ground, in an internal and external environment, simulating the use of EWC in daily life.

\section{Results and discussion}

In the system operation, the control circuit receives analogic signals (variation in amplitude voltage over time) from the joystick, containing horizontal (A1) and vertical position (A0) information. Figure 2 shows a component cursor that can be manipulated by the user. Analogic signals (voltage between 0 and $5 \mathrm{~V}$ ) are read by analogic port of Arduino. This is possible because the microcontroller has an analogic to digital (A/D) converter of 10 bits. The analogic values at the input of the Arduino cause a digital variation between 0 and 1023 value of relative programming variable. This variation corresponds linearly to the mechanical position of the joystick cursor When the joystick cursor is in the center (rest position), the values read by the analog input are in a range from 519 to A1 and from 500 to $\mathrm{A} 0$.

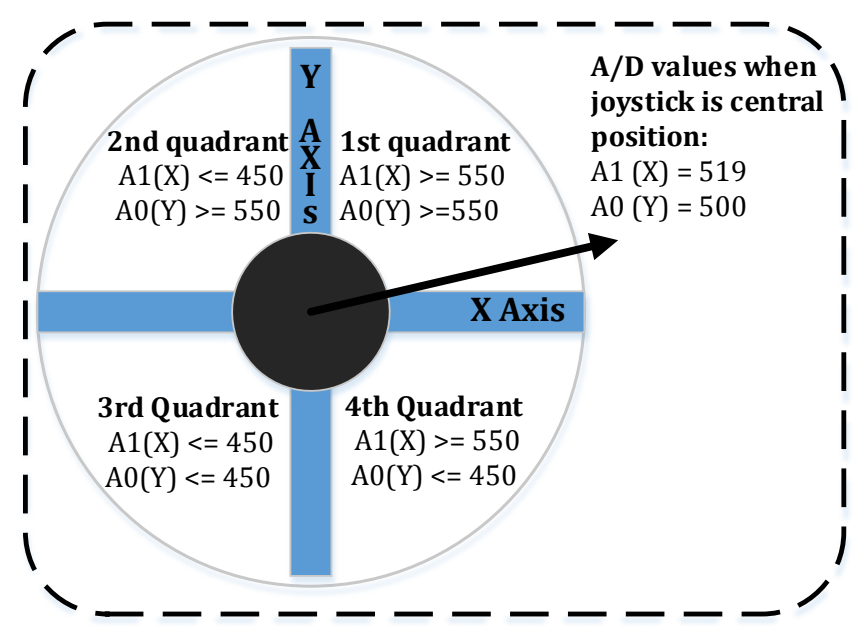

Figure $2 \mathrm{~A} / \mathrm{D}$ values as a function of joystick position

The embedded software was developed using state machine (switch-case) and level tests with if-else in an infinite loop. Within this loop the program may use eight distinct situations, each defined by a subroutine. In the flowchart (Figure 3 ) of the embedded program the "A" function represents a range of options where the wheelchair performs rotational movement under the axle (one wheel rotates forward and the other one rotates backward) or curve movement (the two wheels turn in the same direction, but one spins faster than the other one). The speed and direction of rotation of the motors depend on the $\mathrm{X}$ and $\mathrm{Y}$ position of the Joystick. The control system showed to be very efficient during the execution of the performance tests, for the execution of movements in different directions, but presented a problem in $11.11 \%$ of the cases due to the small deviation during the straight movement.

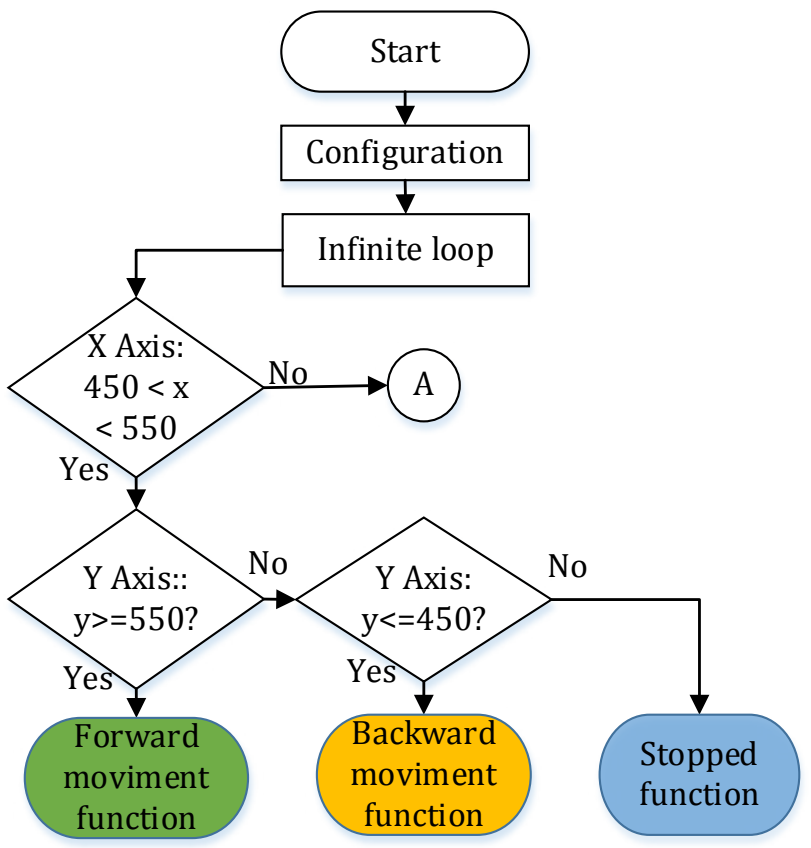

Figure 3 Flowchart of the embedded software.

The total cost considering just components for the construction of the electronic system (batteries, motors, drivers, joystick, plastic box, and other components like capacitors, resistors, voltage regulator, among others) was USD 300.00. Studies indicate the use of the Arduino platform as the basis of a low cost control system for DC motors in EWC. ${ }^{6,7,9,10}$ The advantages of using Arduino are the low cost (USD 22.00) and the possibility of working together with Shields, which are accessory boards such as sensors, display, joystick and control drivers (H-bridge). The joystick exceeded the expectations, presenting low cost (USD 3.95) and ease of application in the circuit and use. The component presented a linear response of voltage variation $(0$ to $5 \mathrm{~V})$ at its $\mathrm{X}$ and $\mathrm{Y}$ outputs as a function of the mechanical displacement of the joystick. This is because internally there are two potentiometers configured as voltage divider, which vary the resistance in proportion to the displacement of the joystick cursor, converting the mechanical displacement to electric voltage. ${ }^{7,10}$

\section{Conclusion}

An electronic control system for children EWC was developed and its functionality evaluated. The methodology employed was successful in the development of a functional and low cost system. The device is replicable and has high potential to assist the low-income population to get access to a motorized wheelchair. ${ }^{11,12}$

\section{Acknowledgements}

To the company Tigre and Jaguaribe for donation of the material. This research has been supported by Brazilian National Research Council $(\mathrm{CNPq})$ and Coordination for the Improvement of Higher Education Personnel (CAPES). 


\section{Conflict of interest}

The author declares no conflict of interest.

\section{References}

1. Ameratunga SN, Norton RN, Bennet DA, et al. Risk of disability due to car crashes: a review of the literature and methodological issues. Injury. 2004;35(11):1116-1127.

2. Khasnabis C, Mines K. Wheelchair service training package: basic level. World Health Organization; 2012.

3. Cooper RA, Ohnabe H, Hobson DA. An Introduction to Rehabilitation Engineering. 1st ed. USA: CRC Press; 2006. 407 p.

4. Batavia M (2010) The wheelchair evaluation: a clinician's guide. Jones \& Bartlett Learning, USA, pp. 276

5. UNICEF. The right to learn: Empowering advances and reducing inequalities. Situation of Brazilian childhood and adolescence. Brasília: United Nations Children's Fund; 2009.

6. Caporal RM, Leon AV, Flores RO, et al. Digital controller for an electric wheelchair based on a low-cost hardware. IEEE Latin America Transactions. 2015;13(10):3221-3227.
7. Arboleda ER, Alegre MCT, Idica KF. Development of a low-cost electronic wheelchair with obstacle avoidance feature. Journal of Mechatronics Electrical Power and Vehicular Technology. 2015;6(2):8996.

8. Argote I, Archila JF, Higuti VAH, et al. Projeto mecatrônico de um rover para aplicação na análise de solos usando tecnologia LIBS - Parte II. Anais do Simpósio Nacional de Instrumentação Agropecuária; 2014. p. $123-126$.

9. Lopes FL, Amorin HAD, Kunkel ME. Comparison between two prototypes of low-cost motorized infant wheelchair built with PVC tubes and Arduino. XVII brazilian congress of biomechanics, Brazil: 2017.

10. Skraba A, Kolozvari A, Kofjac D, et al. Prototype of speech-controlled cloud based wheelchair platform for disabled persons. In Embedded Computing (MECO), $3^{\text {rd }}$ Mediterranean Conference; Montenegro: IEEE; 2014. p. 162-165.

11. Biomecanica e Forense UNIFESP. Construction of an electric wheelchair for children's; 2015.

12. Infineon Technologies. Datasheet BTS 7960 Rev 1.1. Neubiberg: 2004. 